\title{
EVIDÊNCIAS DE ISOMORFISMO E DECOUPLING NA GESTÁO DE CONTROLADORIAS MUNICIPAIS DO ESTADO DE MINAS GERAIS
}

\author{
Gabriela Brandão Lopes' \\ Josiel Lopes Valadares ${ }^{2}$ \\ Ricardo Rocha de Azevedo ${ }^{3}$ \\ Antônio Carlos Brunozi Júnior ${ }^{4}$
}

Resumo: A pesquisa analisa as práticas em operação em sistemas de controle interno de municípios, buscando fatores que explicariam sua institucionalização nos governos municipais de Belo Horizonte e Uberlândia. A pesquisa valeu-se de dados coletados por meio de documentos, observação direta e entrevistas em profundidade, os quais foram analisados utilizando-se a técnica de Análise de Conteúdo. Os resultados indicam que mecanismos isomórficos, coercitivos, miméticos e normativos são utilizados no processo de institucionalização de novas práticas de controle interno nos governos subnacionais analisados, sendo as práticas adotadas sobretudo em decorrência de pressões e monitoramento de órgãos externos de controle, como os Tribunais de Contas. Além disso, percebeu-se em Belo Horizonte a autonomia organizacional da entidade, que busca por legitimação perante outros órgãos, e em Uberlândia foram constatados fatores contingenciais que prejudicam a institucionalização de novas práticas de controle, conjugados à sobrecarga de serviços operacionais para o setor, o que limita a execução de trabalhos técnicos. Nem todas as práticas de controle estão efetivamente institucionalizadas o que permitiu inferir que essas são adotadas apenas de modo cerimonial, ou seja, há presença do decoupling em práticas de controle concomitante, sobretudo na controladoria de Uberlândia. Os resultados ainda indicam que há resistência dos servidores à adoção de novas práticas de controle interno, o que influencia no seu processo de institucionalização. Percebeu-se nesse trabalho que o bom desempenho das atividades do controle interno em governos locais tende a estar relacionado à sua estrutura organizacional, autonomia, independência e existência de atores capacitados, experientes e com poder, o que aumenta o capital institucional da organização e, por consequência, sua efetividade.

Palavras-chave: Controle Interno; Administração Pública; Governo Municipal; Teoria Institucional.

1 gabrielablopes52@gmail.com. Universidade Federal de Viçosa- UFV Campus Viçosa. Viçosa-MG. Brasil. https://orcid.org/0000-0001-9214-3364

2 josiel.valadares@ufv.br. Universidade Federal de Vicosa- UFV Campus Viçosa. Viçosa-MG. Brasil. https://orcid.org/0000-0002-2559-9617

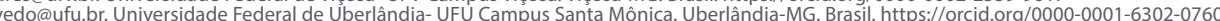

4 antonio.brunozi@ufv.br. Universidade Federal de Viçosa- UFV Campus Viçosa. Viçosa-MG. Brasil. https://orcid.org/0000-0001-9372-6246

- DOI: http://dx.doi.org/10.14392/asaa.2020130205

- Artigo submetido em: 11/10/2019. Revisões requeridas em: 01/06/2020. Aceito em: 12/07/2020. 


\section{EVIDENCE OF ISOMORPHISM AND DECOUPLING IN THE MANAGEMENT OF MUNICIPAL CONTROLLERS OF THE STATE OF MINAS GERAIS}

Abstract:This research analyzes the practices in operation in internal control systems of municipalities, looking for factors that would explain their institutionalization in the municipal governments of Belo Horizonte and Uberlândia. The research used documental data, direct observation and in-depth interviews, which we analyzed by Content Analysis technique. The results indicate that isomorphic, coercive, mimetic and normative mechanisms are used in the process of institutionalization of new internal control practices in the subnational governments analyzed, being the practices adopted mainly due to pressure and monitoring of external control bodies, such as the Courts of. Accounts. Moreover, in Belo Horizonte, the organizational autonomy of the entity, which seeks legitimization before other bodies, was observed, and in Uberlândia, contingency factors were found that hinder the institutionalization of new control practices, combined with the overload of operational services for the sector. This limits the execution of technical work. Not all control practices are effectively institutionalized, which allowed us to infer that they are adopted only in a ceremonial manner, that is, there is the presence of decoupling in concomitant control practices, especially in Uberlândia controllership. The results also indicate that there is resistance from employees to the adoption of new internal control practices, which influences their institutionalization process. It was noticed in this work that the good performance of internal control activities in local governments tends to be related to their organizational structure, autonomy, independence and the existence of qualified, experienced and powerful actors, which increases the institutional capital of the organization and, consequently, its effectiveness.

Keywords: Internal control; Public administration; Municipal government; Institutional theory. 


\section{INTRODUÇÃO}

O sistema de controle interno na administração pública é considerado um instrumento de aprimoramento da gestão pública. Os diversos controles criados a partir desse sistema contribuem para uma maior eficiência e qualidade do setor público, pelo seu potencial aprimoramento do desempenho das organizações públicas (Alves \& Moraes, 2016), sendo reconhecido como uma ferramenta de autocontrole governamental (O'Donnell, 1988), o que possibilitaria a responsabilização dos gestores públicos (Castro, 2015).

Apesar da previsão constitucional da exigência de organização de sistemas de controles internos por todos os níveis de governos não ser algo recente, ainda verifica-se no país uma grande discrepância entre as estruturas criadas entre os diferentes níveis da esfera federativa (Loureiro et al., 2012). Em âmbito municipal, a instituição de sistemas de controle interno como o modelo de Controladoria Geral Municipal (CGM) tem sido criada em poucos municípios, e a literatura tem indicado baixa efetividade entre aqueles que o instituíram (Teixeira, Cruz \& Silva, 2014; Cruz, Silva \& Spinelli, 2016; Lino, Carvalho, Azevedo \& Aquino, 2019).

A literatura atribui as fragilidades do controle interno a falta de autonomia do setor em governos locais (Cavalcante, Peter \& Machado, 2011), controles internos com atuação cerimonial (Sediyama, Aquino \& Lopes, 2017) e necessidade de atores com poder e capital institucional permanecerem por tempo suficiente nas controladorias para que haja institucionalização de novas práticas de controle (Lino et al., 2019). Além disso, estudos demonstram que o sistema de controle interno e a competência dos servidores públicos influenciam positivamente na qualidade das informações públicas em governos locais (Razak, Abdullah \& Dali, 2017; Mutiara, Fachrudin \& Irawati, 2019; Dewi, Azam \& Yusoff, 2019).

O sistema de controle interno pode ser entendido como um conjunto de práticas a serem adotadas pelas organizações públicas, que derivam de diversas normas gerais, sobretudo Constituição Federal, Lei Federal 4.320/64, e Lei de Responsabilidade Fiscal. As normas gerais estabelecem capacidade de ação aos sistemas de controle, através de competências legais. Porém, para que as competências legais, que são práticas latentes, sejam efetivamente realizadas, essas devem ser organizadas pelos governos. Assim, pode-se analisar as práticas de controle interno como sendo práticas organizacionais, permitindo-se analisá-las sob a lente da literatura de mudanças organizacionais.

A literatura organizacional discute por diversas óticas a mudança organizacional, por meio de diferentes teorias. A teoria organizacional institucional discute que as práticas nas organizações podem ser adotadas não necessariamente em busca de eficiência (Meyer \& Rowan, 1977), mas sim, para legitimar-se externamente, diminuindo escrutínio social. Com isso, práticas são adotadas pelas organizações, sem que sejam efetivamente utilizadas, sobretudo quando há acompanhamento externo, dada a necessidade de aparentar conformidade. Tolbert e Zucker (1996) discutem que práticas emergem de diferentes formas, como uma mudança legal, porém apresentam diferentes níveis de institucionalização.

Nesse contexto, os sistemas de controles internos, como um conjunto de práticas, podem estar executando práticas que derivam de legislação, ou outras que foram criadas internamente, através de ações passadas, cuja repetição e transmissão interna foram sendo institucionalizadas com o tempo. Assim, algumas práticas em operação nos sistemas de controle interno podem estar 'em uso' sem, no entanto, estarem institucionalizadas, e outras podem estar plenamente institucionalizadas. 
Nesse contexto, o objetivo geral da pesquisa é analisar as práticas em operação em sistemas de controle interno de municípios, buscando fatores que explicariam sua institucionalização. Para tanto, por meio da análise de dois estudos de caso, prefeituras de Belo Horizonte e Uberlândia, parte-se da premissa institucional sociológica, em que as ações individuais dos atores carregam um conjunto de valores e crenças que é compartilhado por todos, isso se reflete nas atividades e processos que estes indivíduos executam nas organizações que pertencem, no processo de decisão e interações com os demais indivíduos da entidade (Lino et al., 2019). “A institucionalização ocorre sempre que há uma tipificação recíproca de ações habituais pelos atores sociais" (Berger \& Luckmann, 2002, p. 79).

Segundo Araújo et al. (2017) e Rusnindita et al. (2017), as formas de controle no setor público deveriam ser compreendidas mais profundamente no intuito de abarcar os elementos e práticas que legitimam a atuação dos burocratas, nos seus diferentes níveis. Além disso, motiva-se nas constatações das pesquisas de Cavalcante, Peter e Machado (2011), Olivieri (2016) e Sediyama, Aquino e Lopes (2017), de que os sistemas de controle no setor público têm sido apontados como isomórficos, ou seja, criados a partir de pressões externas, em geral copiando sua estrutura, e com uma conformidade cerimonialista (decoupling), criados apenas para compliance.

As práticas em uso nos sistemas de controle interno podem ter sido adotadas por meio de mecanismos de isomorfismo, a partir de modelos já adotados e validados externamente, como discutido por DiMaggio e Powell (1983). No campo em que as organizações estão inseridas, possuem instituições, normas e práticas validadas por outras organizações, uniformizando os símbolos (Carvalho \& Vieira, 2012). Nesse sentido, Meyer e Rowan (1977) relatam que as organizações são levadas a incorporar práticas e procedimentos aceitos e institucionalizados, a fim de aumentar sua legitimidade perante a sociedade, independente da eficácia imediata dessas práticas e procedimentos.

O decoupling, por sua vez, se traduz em ações e estruturas que atuam apenas com vista à legitimação externa, gerando um descolamento entre o que a legislação prevê e o que de fato é executado, gerando limitações para as finalidades das entidades (Boxenbaum \& Jonsson, 2017). Para Broadbent e Laughlin (2003), a existência de mecanismos de controle com atuação cerimonial pode trazer efeitos contraditórios à sociedade.

A realização desta investigação se justifica por identificar os elementos institucionais associados com a institucionalização de novas práticas de controle interno em âmbito municipal. Além disso, permite-se a reflexão de que o processo de aprimoramento das práticas de controle coexiste no ente público à busca por novas práticas por parte das organizações e podem ser disseminadas por atores legitimados no campo e outras práticas já estabelecidas podem perder sua força e dar espaço à experimentação.

A pesquisa contribui ao discutir e trazer resultados sobre como ocorre a atuação do controle interno em duas prefeituras, apresentando a reflexão do cerimonialismo e do isomorfismo na administração pública, especificamente em setores de controladorias municipais. Para tanto, levantou questões importantes, como: por que algumas práticas são utilizadas "de fachada"? Por que muitas práticas de controle interno, mesmo sendo reguladas, na verdade não têm sido efetivamente executadas? O que são práticas padrões ou de qualidade?

\section{REFERENCIAL TEÓRICO}

\subsection{Teoria Institucional Sociológica: Isomorfismo e Decoupling}

Muitas organizações adotam práticas consideradas adequadas pelo seu campo organizacional de modo falho, inexistente ou inconsistente, ou seja, ocorre um 'desacoplamento' ou “dissociação' entre 
a estrutura e o que é de fato executado pelos servidores. Esse comportamento é conceituado pela teoria institucional como decoupling, que pode ser conceituado como a adoção de modo cerimonial de determinada prática com o intuito de se legitimar no campo organizacional (Meyer \& Rowan, 1977).

Os elementos constitutivos deste campo organizacional são as instituições, normas e práticas validadas por outras organizações, uniformizando os símbolos (Carvalho \& Vieira, 2012). Meyer e Rowan (1977) relatam que as organizações são levadas a incorporar práticas e procedimentos aceitos e institucionalizados, a fim de aumentar sua legitimidade externa, independente da eficácia imediata dessas práticas e procedimentos. A legitimidade é sempre buscada em relação a alguém que se quer legitimar, podendo ser buscada perante a sociedade, ou a atores externos com poder, como o Tribunal de Contas.

Os mecanismos isomórficos são utilizados como meios de se alcançar a legitimidade. No isomorfismo institucional consideram-se os instrumentos que as organizações e os atores sociais utilizam para conseguirem legitimação, poder, adequação econômica e social (DiMaggio \& Powell, 1983). Pode ser visualizado por meio de três mecanismos: coercitivo, mimético e normativo. O mecanismo coercitivo provém da influência política e do problema da legitimidade. Advém das pressões externas, como força da lei ou determinações governamentais, exercida sobre as organizações para que estas adotem procedimentos ou técnicas semelhantes a outras organizações mais fortes (Frumkin \& Galaskiewick, 2004; Boxenbaum \& Jonsson, 2017).

Para Lacombe e Chu (2008), a relação de dependência entre organizações faz com que as organizações consideradas mais fortes, exerçam pressões formais e informais sobre as outras para a adoção de práticas e procedimentos similares. $\mathrm{O}$ isomorfismo mimético advém do contexto de incertezas vividas pelas organizações e que enfrentam conflitos quanto aos seus desígnios. DiMaggio e Powell (1983) relatam que essa difusão de práticas e procedimentos nem sempre é exercido de forma intencional pelas organizações, talvez ela nem se dê conta de que está sendo copiada ou não deseje ser copiada, simplesmente serve de fonte conveniente de práticas que a imitadora pode utilizar e se tornar legítima (Tuttle \& Dillard, 2007).

Outro meio de tornar as organizações homogêneas é por meio das orientações de órgãos profissionais, através do compartilhamento de um conjunto de instituições de trabalho em determinado ramo de ocupação (Kelm, 2014). DiMaggio e Powell (1983) colocam dois aspectos como fontes relevantes desse tipo de isomorfismo. Primeiramente, a educação adquirida por universidades e centros de desenvolvimento do conhecimento e normas, bem como a elaboração de networks de profissionais, sendo um mecanismo de difusão de informações propícios a legitimação perante a sociedade.

De acordo com os neoinstitucionalistas o decoupling ocorre quando organizações adotam políticas oficiais para atendimento às expectativas de seu ambiente institucional, contudo, não implementam os programas devido a conflitos internos ou até mesmo a falta de recursos. O decoupling pode ser visto sob uma perspectiva propositiva, entendido como suporte que as organizações se balizam para proteger seus recursos, reduzindo-se assim os custos de diminuir produtividade. Por outro lado, pode também ser concebido numa perspectiva crítica, ou seja, esta dissociação entre normas e a prática gerencial tem efeito negativo na produtividade e desempenho organizacional (Bae, 2016).

Na visão de Patz (2018), o decoupling serve ao propósito de organizar sistemas de valores conflitantes, dentro e fora da administração, e para garantir o funcionamento eficaz de uma organização que precisa reconciliar vários objetivos e interesses concorrentes. Ou seja, a dissociação entre as normas e ação de atores públicos é decorrente da existência de conflito de valores dentro das organizações públicas. Isto posto, fica evidente o paradoxo existente no corpo burocrático, que por sua vez é evidenciado 
na implementação de políticas públicas. Tomado nesse contexto, o decoupling é representado pela desarticulação operacional entre as macropolíticas - aqui posto no nível da burocracia nacional - e a sua implementação no nível da rua - aqui posto no nível da burocracia municipal (Johnson et al., 2016; Carter et al., 2014). Observa-se que enquanto a estrutura burocrática fornece camadas de supervisão, espera-se que os oficiais das ruas respondam a situações específicas, todas as iterações de impossíveis de incluir nas regras organizacionais formais

As organizações utilizam do comportamento de decoupling para esconder sua não conformidade de práticas, como modo de proteção contra as pressões coercitivas e escapando das regras (Oliver, 1991). Se as atividades executadas pelos indivíduos serão contraditórias as exigências do contexto, ou na presença de problemas de monitoramento e controle das atividades dos servidores, abre-se espaço para que os processos não sejam realmente institucionalizados e as organizações estejam se utilizando desses procedimentos para se legitimarem perante a sociedade (Meyer \& Rowan, 1977).

Portanto, por meio da apresentação desta teoria emergem-se as proposições teóricas utilizadas nesta investigação. Há a consideração da utilização de mecanismos isomórficos pelos órgãos centrais de controle interno em administrações municipais e seus respectivos atores sociais, com o objetivo de se legitimarem perante o seu campo organizacional, sejam órgãos reguladores, profissionais ou até mesmo a sociedade civil (DiMaggio \& Powell, 1983).

Ademais, nem sempre as Controladorias municipais adotam as práticas de controle de modo efetivo, ou seja, muitos procedimentos podem ser adotados de modo cerimonial (decoupling) apenas com o intuito de legitimação (Cavalcante, Peter \& Machado, 2011; Sediyama, Aquino \& Lopes, 2017). A adoção de práticas por busca de legitimação é um assunto discutido e esperado segundo Meyer e Rowan (1977).

\subsection{Sistemas de Controle Interno no Setor Público}

No contexto da administração pública, para que se evite a ocorrência de fraudes e deixe o patrimônio público vulnerável, é necessário aprimorar as ferramentas de controle que abranjam todas as áreas da gestão pública e todas suas atividades (Araújo et al., 2016).

O foco do controle interno é nos processos administrativos do governo e nas condutas dos agentes e na ação do ente público (Castro, 2015). Esse controle é dividido em três técnicas: o controle prévio, o controle concomitante e o controle posterior. O controle prévio é o que antecede a conclusão dos atos, sendo exercido pela contabilidade. O controle concomitante acompanha a realização dos atos públicos e suas respectivas regularidades, sendo a técnica utilizada a de fiscalização. Já no caso do controle subsequente ou posterior, seria após a conclusão dos atos praticados pelos gestores, visando detectar possíveis erros, avaliando a eficiência e eficácia das ações administrativas, cuja técnica utilizada é a auditoria (Castro, 2015).

Lartey, Kong, Bah, Santosh e Gumah (2020) por meio de uma análise das técnicas de controle interno, identificaram por meios estatísticos que o controle preventivo influencia a eficácia dos controle internos nas organizações, no entanto, os outros tipos de controle também são relevantes para detectar o bom funcionamento do controle prévio.

O sistema de controle interno é um instrumento eficaz na geração de receitas públicas, ou seja, quando se possui um controle interno efetivo, há uma minimização entre as receitas orçadas das realizadas (Mohammed, 2018). Outrossim, como demonstram Nogueira e Jorge (2017), é necessário aprimorar os 
procedimentos de controle interno para que seja mantida a confiabilidade e qualidade das informações financeiras e orçamentárias.

O sistema de controle interno deveria ser subordinado hierarquicamente ao chefe da organização pública, tendo como principais atividades o acompanhamento dos instrumentos orçamentários, financeiros, contábeis e patrimoniais, monitorando os atos e fatos públicos para identificação de possíveis riscos (Pederneiras et al., 2018). O controle interno e as auditorias, juntamente com accountability e transparência, são mecanismos de proteção do erário público, sobrevivência econômica do país e importantes meios de comunicação e participação dos cidadãos na Administração Pública (Fernandes, Borges \& Leite Junior, 2017).

Segundo Kewo (2017), o sistema de controle interno é um importante mecanismo em um contexto democrático, da governança pública, estimulando a participação social e a transparência. Ademais, os estudos de Razak, Abdullah e Dali (2017), Mutiara, Fachrudin e Irawati (2019) e Dewi, Azam e Yusoff (2019) concluíram que o sistema de controle interno e a competência dos recursos humanos influenciam de forma positiva na qualidade das informações das demonstrações financeiras de governos locais.

No entanto, a literatura tem identificado algumas fragilidades do sistema de controle interno. Cavalcante, Peter e Machado (2011), por exemplo, tinham o objetivo de analisar os órgãos de controle interno municipais no Estado do Ceará e identificaram a falta de autonomia desses órgãos no exercício de suas atividades o que limita a atuação do controle dos recursos públicos e além disso, constatou que há uma fragilidade da transparência da gestão pública.

Já Sediyama et al. (2017) constataram que os órgãos de controle interno municipais muitas vezes se limitam a emissão e assinatura de pareceres de conformidade para atendimento de legislação, sendo que, necessitam de maior capacidade técnica para a execução de tais atividades na administração pública.

Lino et al. (2019), ao analisar o sistema de controle interno em municípios brasileiros, constataram que há necessidade de atores com poder e capital institucional nas controladorias por tempo suficiente para que haja institucionalização de novas práticas de controle, além disso, fontes de legitimação internas e externas auxiliam na promoção do trabalho institucional e acúmulo desse capital institucional.

Entretanto, Anderson, Maks e Klaassen (2019) identificaram analisando 22 controladorias municipais na Holanda que muitas vezes os controladores gerais são confrontados com solicitações de superiores que vão contra o aparato normativo, e na maioria dos casos estudados, os controladores agiram fora da lei para acatar essas solicitações.

Portanto, identifica-se a necessidade de estudar os sistemas de controle interno em governos locais, investigando as motivações para a institucionalização de suas práticas.

\section{PROCEDIMENTOS METODOLÓGICOS}

A pesquisa foi desenvolvida por meio de dois estudos de caso em controladorias municipais. A seleção dos casos seguiu a estratégia de Matched comparisons (Patton, 2015), em que casos diferentes são comparados para identificar os fatores que explicaram essas diferenças. As unidades de análises foram as Controladorias de Belo Horizonte (BH) e Uberlândia, ambas pertencentes ao Estado de Minas Gerais.

A pesquisa seguiu uma estratégia indutiva, em que as categorias e construtos não foram definidos previamente, mas sim, emergiram durante o desenvolvimento da pesquisa. Esses surgiram durante a pesquisa no campo, a partir das interpretações realizadas em relação às entrevistas, baseados na teoria, que já estava definida previamente (Nowell \& Albrecht, 2019). 
Ambos os municípios são de grande porte populacional e economicamente desenvolvidos, visto que os produtos internos brutos per capta são, em Belo Horizonte, de $\mathrm{R} \$ 34.910,13$ e, em Uberlândia, de R\$44.612,40. Segundo dados da Associação Mineira de Municípios (AMM, 2018), Belo Horizonte, integrante da região central do Estado, é a região mais populosa de Minas Gerais e como atividade econômica predominante o setor de serviços, industrial e agropecuária (AMM, 2018). Já o município de Uberlândia pertencente à região do Triângulo, a geração de renda também possui concentração para o setor de serviços, industrial e agropecuária (Tabela 1).

\begin{tabular}{|c|c|c|}
\hline Características & Belo Horizonte & Uberlândia \\
\hline $\begin{array}{c}\text { Número de Servidores no SCI (núm.) } \\
\text { Efetivos (\%) } \\
\text { Comissionados (\%) }\end{array}$ & $\begin{array}{c}110 \\
79,09 \\
20,91\end{array}$ & $\begin{array}{c}32 \\
81,25 \\
18,75\end{array}$ \\
\hline $\begin{array}{l}\text { Experiência da Equipe em Anos } \\
\text { (Mínimo e Máximo) }\end{array}$ & $\begin{array}{c}1 \text { ano e } 8 \text { meses } \\
13 \text { anos }\end{array}$ & $\begin{array}{c}1 \text { ano e } 8 \text { meses } \\
22 \text { anos }\end{array}$ \\
\hline Ano de Implantação do SCl e da Controladoria & 2005 & $\begin{array}{c}\mathrm{SCl}-1994 \\
\text { Controladoria-2009 }\end{array}$ \\
\hline Controlador-Geral atual & $\begin{array}{l}\text { Nomeado, cedido pelo TCE-MG } \\
\text { desde } 2017\end{array}$ & $\begin{array}{l}\text { Procurador na Prefeitura, nomeado na } \\
\text { função desde } 2017\end{array}$ \\
\hline Possui Normas Locais de Auditoria? & Sim & Sim \\
\hline Utiliza Matriz de Riscos? & Sim & Não \\
\hline Vinculação hierárquica do SCI & Gabinete do Prefeito & Secretaria de Governo \\
\hline Comunicação com órgãos de controle & Direta/Pessoal & Telefone/e-mail \\
\hline Escândalos recentes de corrupção? & Não & Não \\
\hline
\end{tabular}

Nota. Elaboração própria, com base na pesquisa de campo, IBGE cidades e IMRS - dados da Fundação João Pinheiro.

Neste estudo, adotou-se os métodos da análise documental, observação direta e entrevistas em profundidade como técnicas de coletas de dados e essas escolhas se deram com o intuito de minimizar os riscos de dados e conclusões erradas ou distorcidas da realidade (Mckinnon, 1988; Eisenhardt, 1989).

Na pesquisa documental, foram analisadas oito leis, treze decretos, duas Portarias, uma Instrução Normativa, uma Decisão Normativa, dois Manuais, dois Relatórios e dois Memorandos Circulares normativas das prefeituras e do Tribunal de Contas do Estado de Minas Gerais. Esses são todos os documentos disponíveis sobre a regulamentação do sistema de controle interno em âmbito municipal e suas respectivas atividades.

Em uma segunda etapa, após o levantamento documental, partiu-se para os encontros in loco nos municípios e o contato direto com os servidores. A técnica utilizada para coleta dos dados foi entrevista em profundidade, com os diários de campo (Robles, 2011). No total foram 17 entrevistados, com uma média de duração das entrevistas de 40 minutos. A Tabela 2 apresenta a experiência dos servidores entrevistados nos dois casos. Vale ressaltar que foi utilizada a técnica snowball sampling (bola de neve) para a realização das entrevistas (Who, 1994). Por esta técnica, os atores entrevistados indicaram outros atores para complementar a análise até que o objetivo do estudo tenha condições de ser compreendido, chamado" ponto de saturação", demonstrando o fim das entrevistas por meio do esgotamento e repetição de respostas, ou seja, estagnação, sem acrescentar informações relevantes ao estudo (Who, 1994). 
Tabela 1 - Apresentação dos Casos Analisados

\begin{tabular}{|c|c|c|}
\hline Características & Belo Horizonte & Uberlândia \\
\hline $\begin{array}{c}\text { Número de Servidores no SCI (núm.) } \\
\text { Efetivos (\%) } \\
\text { Comissionados (\%) }\end{array}$ & $\begin{array}{c}110 \\
79,09 \\
20,91\end{array}$ & $\begin{array}{c}32 \\
81,25 \\
18,75\end{array}$ \\
\hline $\begin{array}{l}\text { Experiência da Equipe em Anos } \\
\text { (Mínimo e Máximo) }\end{array}$ & $\begin{array}{c}1 \text { ano e } 8 \text { meses } \\
13 \text { anos }\end{array}$ & $\begin{array}{c}1 \text { ano e } 8 \text { meses } \\
22 \text { anos }\end{array}$ \\
\hline Ano de Implantação do SCl e da Controladoria & 2005 & $\begin{array}{c}\text { SCl-1994 } \\
\text { Controladoria-2009 }\end{array}$ \\
\hline Controlador-Geral atual & $\begin{array}{c}\text { Nomeado, cedido pelo TCE-MG } \\
\text { desde } 2017\end{array}$ & $\begin{array}{l}\text { Procurador na Prefeitura, nomeado na } \\
\text { função desde } 2017\end{array}$ \\
\hline Possui Normas Locais de Auditoria? & Sim & Sim \\
\hline Utiliza Matriz de Riscos? & Sim & Não \\
\hline Vinculação hierárquica do SCI & Gabinete do Prefeito & Secretaria de Governo \\
\hline Comunicação com órgãos de controle & Direta/Pessoal & Telefone/e-mail \\
\hline Escândalos recentes de corrupção? & Não & Não \\
\hline
\end{tabular}

Nota. Elaboração própria, com base na pesquisa de campo, IBGE cidades e IMRS - dados da Fundação João Pinheiro.

Neste estudo, adotou-se os métodos da análise documental, observação direta e entrevistas em profundidade como técnicas de coletas de dados e essas escolhas se deram com o intuito de minimizar os riscos de dados e conclusões erradas ou distorcidas da realidade (Mckinnon, 1988; Eisenhardt, 1989).

Na pesquisa documental, foram analisadas oito leis, treze decretos, duas Portarias, uma Instrução Normativa, uma Decisão Normativa, dois Manuais, dois Relatórios e dois Memorandos Circulares normativas das prefeituras e do Tribunal de Contas do Estado de Minas Gerais. Esses são todos os documentos disponíveis sobre a regulamentação do sistema de controle interno em âmbito municipal e suas respectivas atividades.

Em uma segunda etapa, após o levantamento documental, partiu-se para os encontros in loco nos municípios e o contato direto com os servidores. A técnica utilizada para coleta dos dados foi entrevista em profundidade, com os diários de campo (Robles, 2011). No total foram 17 entrevistados, com uma média de duração das entrevistas de 40 minutos. A Tabela 2 apresenta a experiência dos servidores entrevistados nos dois casos. Vale ressaltar que foi utilizada a técnica snowball sampling (bola de neve) para a realização das entrevistas (Who, 1994). Por esta técnica, os atores entrevistados indicaram outros atores para complementar a análise até que o objetivo do estudo tenha condições de ser compreendido, chamado " ponto de saturação", demonstrando o fim das entrevistas por meio do esgotamento e repetição de respostas, ou seja, estagnação, sem acrescentar informações relevantes ao estudo (Who, 1994).

Tabela 2 - Entrevistados por cargo e experiência

\begin{tabular}{|c|c|c|}
\hline \multicolumn{2}{|c|}{ Experiência no controle } & Experiência na controladoria \\
\hline \multicolumn{3}{|c|}{ Belo Horizonte / MG } \\
\hline E1 & 22 anos no TCE/MG & 1 ano e 10 meses \\
\hline E2 & 19 anos no TCE/MG & 1 ano e 10 meses \\
\hline E3 & 2 anos como estagiário na Prefeitura de BH & 1 ano \\
\hline E4 & 10 anos no TCE/MG & 1 ano e 10 meses \\
\hline E5 & 1 ano e 10 meses & 1 ano e 10 meses \\
\hline E6 & 7 anos exercendo advocacia foco "direito público" & 10 meses \\
\hline E7 & 10 anos & 10 anos \\
\hline E8 & 33 anos & Entre os anos 2005 e 2006 \\
\hline \multicolumn{2}{|c|}{ Uberlândia / MG } \\
\hline
\end{tabular}




\begin{tabular}{|c|c|c|}
\hline E9 & 12 anos na prefeitura de Uberlândia & 1 ano e 10 meses \\
\hline E10 & 1 ano e 10 meses & 1 ano e 10 meses \\
\hline E11 & 25 anos & 22 anos \\
\hline E12 & 5 anos e 11 meses & 1 anos e 11 meses 10 meses \\
\hline E13 & 4 anos & 1 ano e 10 meses \\
\hline E14 & 4 anos & 5 anos \\
\hline E15 & 5 anos & 13 anos \\
\hline E16 & 25 anos & 14 anos na Controladoria de Uberlândia. \\
\hline E17 & 15 anos na prefeitura de Uberlândia & \\
\hline
\end{tabular}

Para complementar o processo de triangulação dos dados e obter uma maior profundidade no processo dessa pesquisa, foi adotada em todo o período de pesquisa de campo, como técnica de coleta de dados, a observação direta (Maffezzolli \& Boehs, 2008). Para sua operacionalização, foram construídas anotações de campo. Esse instrumento foi um importante método de registro dos dados e forneceu os meios pelos quais a pesquisa pode ser gerenciada de modo que, fosse controlado o viés do pesquisador observador.

A pesquisa de campo na controladoria do município de $\mathrm{BH}$ ocorreu no período de 07 de agosto a 10 de outubro de 2018. Nesse período ocorreram as entrevistas com os servidores e as observações do contexto social. Já no município de Uberlândia, a pesquisa no campo foi realizada entre 29 de agosto e 16 de outubro de 2018. Esses períodos foram de modo presencial, ou seja, o pesquisador se inseriu no contexto dos entrevistados. Adicionalmente, houve contatos via telefone e e-mail para solicitação de documentos e informações complementares para as análises.

Para análise dos dados foi utilizada a técnica de análise de conteúdo ou análise categorial. Na Tabela 3 são expostas as categorias de análise do artigo.

Tabela 3 - Categorias Teóricas para análise dos resultados

\begin{tabular}{|c|c|}
\hline $\begin{array}{c}\text { Premissa central } \\
\text { Institucionalização: Isomorfismo ou Decoupling de Práticas de } \\
\text { Controle Interno }\end{array}$ & Práticas de Controle em uso (institucionalizadas e não institucionalizadas) \\
\hline & Fatores Associados na Institucionalização e à não Institucionalização \\
\hline & Carriers (transportes de valores institucionais) \\
\hline & Decoupling (adoção cerimonial) \\
\hline & Mecanismos Isomórficos \\
\hline & Resistência dos Atores \\
\hline & Legitimação Externa \\
\hline & Eficiência Organizacional \\
\hline
\end{tabular}

Fonte: Elaborado pelos autores.

$\mathrm{Na}$ análise, foram explorados os documentos e falas dos atores envolvidos na pesquisa de campo, ou seja, por meio de aspectos linguísticos e documentais. Há ainda de se destacar que se adotaram alguns pressupostos teóricos como necessários para se considerar práticas e procedimentos como institucionalizados em organizações, visto que, nem todas as práticas e processos são institucionalizados nas controladorias públicas. Na Tabela 4 é apresentado um checklist de pressupostos necessários para fazer essa caracterização. 
Tabela 4 - Critérios Adotados que Definem uma Prática ou Processo Institucionalizado.

\begin{tabular}{|c|c|}
\hline Critérios & Autores \\
\hline $\begin{array}{l}\text { Práticas que já se tornaram rotineiras e foram aceitas pelos indivíduos (codificação, incorporação, } \\
\text { reprodução, institucionalização) }\end{array}$ & Burns; Scapens (2000) \\
\hline Práticas que se caracterizam como algo que prevalece e permanece (hábitos, rotinas e instituições) & Guerreiro; Pereira; Frezatti (2008) \\
\hline $\begin{array}{l}\text { Práticas utilizadas em longo prazo que são transmitidas aos novos indivíduos (a perpetuação de } \\
\text { processos no decorrer de um tempo consideravelmente longo) }\end{array}$ & Tolbert; Zucher (1996) \\
\hline $\begin{array}{l}\text { Se a legislação perder a vigência, as práticas continuam serem executadas, se existe necessidade de } \\
\text { coerção, não está institucionalizado }\end{array}$ & Berger e Luckman (1967) \\
\hline Práticas sobreviventes por várias gerações de membros da organização & Tolbert; Zucher (1996) \\
\hline
\end{tabular}

Fonte: Elaborado segundo os autores apresentados.

\section{RESULTADOS E DISCUSSÕES}

Na Tabela 5 estão apresentadas as práticas e tipos de controle em uso e quais são os procedimentos institucionalizados nos respectivos órgãos, que emergiram a partir das análises e entrevistas.

Tabela 5 - Práticas de Controle Interno em uso no momento pelas Controladorias analisadas

\begin{tabular}{|c|c|c|c|c|c|c|}
\hline \multirow{2}{*}{ Prática Analisada } & \multirow{2}{*}{ Tipo de Informação } & \multirow{2}{*}{ Abrangência da Norma } & \multicolumn{2}{|c|}{ Em Uso } & \multicolumn{2}{|c|}{ Institucionalizada } \\
\hline & & & $\mathrm{BH}$ & UDI & BH & UDI \\
\hline Acompanhamento da execução do orçamento & Orçamentária & Norma geral & Sim & Não & Sim & Não \\
\hline Prestação de contas ou Tomada de Contas Especial & Prestação de Contas & Norma geral & Sim & Não & Sim & Não \\
\hline $\begin{array}{l}\text { Verificação da legalidade dos atos orçamentários (prévio, } \\
\text { concomitante e subsequente) }\end{array}$ & Orçamentária & Norma geral & Sim & Não & Sim & Não \\
\hline Avaliação dos resultados alcançados pelo gestor público & Prestação de Contas & Norma geral & Sim & Sim & Sim & Não \\
\hline $\begin{array}{l}\text { Fiscalização contábil, financeira, orçamentária, operacional e } \\
\text { patrimonial das adm. direta e indireta }\end{array}$ & Fiscalização & Norma geral & Sim & Sim & Sim & Sim \\
\hline Acompanhamento da renúncia de receitas & Orçamentária & Norma geral & Sim & Não & Sim & Não \\
\hline Acompanhamento das subvenções & Terceiro Setor & Norma geral & Sim & Sim & Sim & Sim \\
\hline Avaliar o cumprimento das metas do PPA & Orçamentária & Norma geral & Sim & Não & Sim & Não \\
\hline Acompanhar a execução dos programas de governo & Orçamentária & Norma geral & Sim & Não & Sim & Não \\
\hline $\begin{array}{c}\text { Avaliar a aplicação de recursos públicos em entidades } \\
\text { privadas }\end{array}$ & Terceiro Setor & Norma geral & Sim & Sim & Sim & $\operatorname{Sim}$ \\
\hline Controlar as operações de crédito & Orçamentária & Norma geral & Sim & Sim & Sim & Sim \\
\hline $\begin{array}{l}\text { Orientar, acompanhar, fiscalizar e avaliar gestão orçamentá- } \\
\text { ria, patrimonial, financeira da adm. direta e indireta }\end{array}$ & Controle & Norma local-UDI & Não & Não & Não & Não \\
\hline $\begin{array}{l}\text { Elaborar e submeter ao prefeito estudos para a racionaliza- } \\
\text { ção da despesa e arrecadação da receita orçada }\end{array}$ & Orientação & Norma local-UDI & Não & Sim & Não & $\operatorname{Sim}$ \\
\hline $\begin{array}{c}\text { Acompanhar a execução física e financeira dos programas } \\
\text { de governo }\end{array}$ & Orçamentária & Norma local-UDI & Não & Não & Não & Não \\
\hline $\begin{array}{c}\text { Subsidiar a elaboração do processo de planejamento } \\
\text { municipal }\end{array}$ & Orçamentária & Norma local-UDI & Não & Não & Não & Não \\
\hline Executar auditorias operacionais, contábil e administrativas & Controle & Norma local-UDI & Não & Sim & Não & Não \\
\hline Verificar e certificar as contas do gestor público & Controle & Norma local-UDI & Não & Sim & Não & $\operatorname{Sim}$ \\
\hline Procedimento Administrativo Disciplinar (PAD) & Controle & Norma local-BH & Sim & Não & Sim & Não \\
\hline Procedimento Preliminar de Apuração (PPA) & Controle & Norma local-BH & Sim & Não & Sim & Não \\
\hline Transparência ativa (receitas e despesas) & Transparência & Norma geral & Sim & Não & Sim & Não \\
\hline Assinar o Relatório de Gestão Fiscal & Prestação de Contas & Norma geral & Sim & Sim & Sim & Sim \\
\hline Fiscalizar o atingimento das metas estabelecidas na LDO & Orçamentária & Norma geral & Sim & Não & Sim & Não \\
\hline $\begin{array}{l}\text { Fiscalizar os limites e condições para realização de operações } \\
\text { de crédito e inscrição de restos a pagar }\end{array}$ & Fiscalização & Norma geral & Sim & Sim & Sim & Não \\
\hline $\begin{array}{c}\text { Conduzir os montantes de dívidas e despesa com pessoal } \\
\text { aos respectivos limites }\end{array}$ & Fiscalização & Norma geral & Sim & Sim & Sim & Não \\
\hline $\begin{array}{l}\text { Auditoria contábil, financeira, orçamentária, operacional e } \\
\text { patrimonial na adm. direta e indireta }\end{array}$ & Controle & Norma estadual & Sim & Não & Sim & Não \\
\hline $\begin{array}{l}\text { Emitir relatório, certificado de auditoria e parecer que consig- } \\
\text { narão qualquer irregularidade e ilegalidade }\end{array}$ & Controle & Norma estadual & Sim & Não & Sim & Não \\
\hline
\end{tabular}




\begin{tabular}{|c|c|c|c|c|c|c|}
\hline $\begin{array}{l}\text { Indicar as medidas necessárias para corrigir as falhas } \\
\text { encontradas }\end{array}$ & Controle & Norma estadual & Sim & Não & Sim & Não \\
\hline $\begin{array}{c}\text { Alertar a autoridade competente para que adote as medidas } \\
\text { de ressarcimento ao erário, e se não obter, instaurar tomada } \\
\text { de contas especial }\end{array}$ & Controle & Norma estadual & Sim & Não & Sim & Não \\
\hline $\begin{array}{l}\text { Fornecer ao Tribunal informações relativas ao planejamento, } \\
\text { execução e resultados de suas ações }\end{array}$ & Prestação de Contas & Norma estadual & Sim & Sim & Sim & Sim \\
\hline $\begin{array}{c}\text { Encaminhar ao Tribunal o plano de auditorias para o } \\
\text { exercício subsequente, bem como os respectivos relatórios } \\
\text { de auditoria. }\end{array}$ & Prestação de Contas & Norma estadual & Sim & Não & Sim & Não \\
\hline $\begin{array}{l}\text { Elaborar relatório de prestação de contas anuais do Prefeito } \\
\text { com caráter conclusivo sobre a gestão }\end{array}$ & Prestação de Contas & Norma estadual & Sim & Sim & Sim & Sim \\
\hline $\begin{array}{l}\text { Procedimentos de detecção, concomitante ou a posteriori, } \\
\text { de erros, omissões, inadequações e intempestividade da } \\
\text { informação contábil. }\end{array}$ & Controle & Norma geral & Sim & Não & Sim & Não \\
\hline $\begin{array}{l}\text { Disponibilizar ao cidadão informações como resultados } \\
\text { de auditorias, inspeções, prestações e tomadas de contas } \\
\text { incluindo prestações de contas anteriores }\end{array}$ & Transparência & Norma geral & Sim & Não & Sim & Não \\
\hline Supervisionar e executar auditorias, inspeções físicas & Controle & Norma local-BH & $\operatorname{Sim}$ & Não & $\operatorname{Sim}$ & Não \\
\hline $\begin{array}{l}\text { Executar auditorias contábil, patrimonial, orçamentária, } \\
\text { financeira, administrativa, de suprimento de bens e serviços, } \\
\text { RH, Tl, obras e serviços de engenharia }\end{array}$ & Controle & Norma local-BH & Sim & Não & Sim & Não \\
\hline Fiscalizar o cumprimento do Código de ética dos servidores & Fiscalização & Norma local-BH & Sim & Não & Sim & Não \\
\hline $\begin{array}{l}\text { Monitorar e fiscalizar o cumprimento da LAI e promover } \\
\text { treinamento de práticas de transparência }\end{array}$ & Transparência & Norma local-BH & Sim & Não & Sim & Não \\
\hline $\begin{array}{l}\text { Procedimento administrativo de sanções em casa de fraudes } \\
\text { em licitações e compras }\end{array}$ & Controle & Norma local-BH & Sim & Não & Sim & Não \\
\hline $\begin{array}{l}\text { Instaurar sindicância em Processos Administrativo de Apura- } \\
\text { ção de fraudes e corrupção }\end{array}$ & Controle & Norma local-BH & Sim & Não & Sim & Não \\
\hline Monitoramento das parcerias pública privada & Terceiro Setor & Norma local-UDI & na & Sim & Sim & Sim \\
\hline Regularização de credores do município & Controle & Norma local-UDI & na & Não & Sim & Não \\
\hline Auditoria de Preços e Necessidade da Despesa Pública & Controle & Norma local-UDI & na & Sim & Sim & Sim \\
\hline Procedimentos de integridade da adm. Municipal & Controle & Norma local-BH & Sim & Não & Sim & Não \\
\hline $\begin{array}{l}\text { Procedimento de sindicância em caso de enriquecimento } \\
\text { ilícito de servidor municipal }\end{array}$ & Controle & Norma local-BH & Sim & Não & Sim & Não \\
\hline Procedimentos de gestão de riscos com base no COSO & Controle & Norma local-BH & Sim & Não & Não & Não \\
\hline $\begin{array}{l}\text { Aluno auditor-estímulo de cidadania e auditoria em âmbito } \\
\text { escolar municipal }\end{array}$ & Transparência & Norma local- BH & Sim & Não & Sim & Não \\
\hline $\begin{array}{c}\text { Ouvidor jovem- alunos eleitos por estudantes a represen- } \\
\text { tarem os estudantes e fazem solicitaçōes via sistema da } \\
\text { ouvidoria municipal }\end{array}$ & Transparência & Norma local- BH & Sim & Não & Sim & Não \\
\hline $\begin{array}{l}\text { "Um por todos e todos por um"- material voltado para a } \\
\text { cidadania e ética com crianças }\end{array}$ & Transparência & Norma local- BH & Sim & Não & Sim & Não \\
\hline
\end{tabular}

Fonte: Elaborado segundo os autores apresentados.

Os resultados da Tabela 5 indicam que os controles associados à transparência pública têm recebido maior foco no município de Belo Horizonte. Fato que pode ser compreendido pela Controladoria de Belo Horizonte ser o órgão responsável pelas atividades de transparência municipal, e no caso da prefeitura de Uberlândia essa atribuição não pertence ao setor de controle interno.

Percebe-se, por meio das análises, que o fato de algumas práticas serem mais monitoradas pelo TCE/MG e CGU, tais como aquelas de controle interno acompanhadas periodicamente pelos atores de poder no campo organizacional, é um fator que favorece a institucionalização nos casos analisados. Ressalta-se que o fato de haver a necessidade de coerção, demonstra que o processo institucional não ocorreu por completo, de modo que, se a legislação perdesse a vigência ou os órgãos priorizassem outros procedimentos de controle interno para fiscalizar, essas práticas perderiam o 'Sim' habitual. Ademais, uma das etapas para institucionalização de práticas é a sua repetição (Burns \& Scapens, 2000). Assim, a ação de monitoramento por órgãos como CGU/TCU pode auxiliar na institucionalização de práticas de controle interno.

Outro fator importante identificado nas análises é a continuidade histórica de práticas de controle no decorrer de diversas gerações de servidores, assim como a continuidade de estrutura organizacional 
de servidores, como já constatado no estudo de Lino et al., (2019). O fato de a maioria dos servidores do controle interno de Belo Horizonte, especificamente dos setores de auditoria e corregedoria, serem efetivos, reduz as possibilidades de descontinuidade do processo de institucionalização nas trocas de gestão dos chefes do poder executivo. Isso já era um fator esperado, segundo Tolbert e Zucker (1996), quando afirmam a importância da continuidade histórica da estrutura da organização para que as instituições sobrevivam às várias gerações de servidores da organização. Assim, a existência de estruturas de carreiras estáveis favorece a institucionalização de práticas.

O SCl de Belo Horizonte possui um controle concomitante atuante, seja ele in loco, através de, por exemplo, visitas técnicas em obras, no dia a dia das secretarias, entre outros aspectos, conforme evidencia o E1. Outra questão importante que emerge da fala do respondente 1, para a institucionalização de práticas, é a existência de fluxos de informações claramente definidos, com utilização de formulários. Os formulários e os fluxos podem atuar como carriers de valores institucionais, na medida em que transmitem prontamente a novos servidores as atividades "que devem ser feitas por aqui". Dessa forma, para que práticas sejam institucionalizadas, a definição dos fluxos de informações é um aspecto importante para as controladorias.

Já o SCl de Uberlândia tem foco no controle prévio e operacional, não possuindo o hábito de realizar visitas técnicas e o controle concomitante, tendo essa rotina sido instituída apenas a partir de 2017, com a nova gestão do controle municipal. E9 apresenta essa constatação de modo evidente:

E9: "Ao longo do tempo, se estabeleceu uma cultura que seria mais ou menos assim:"podemos errar que a controladoria vai achar esse erro", então ao longo do tempo, a controladoria demandou muita energia no controle primário, e se distanciou muito do controle macro que é aquele do acompanhamento, dos resultados, do sucesso, das ações orçamentárias por exemplo, e de auditorias in loco, bem como perdeu um pouco a chance de ter mais manuais, então nesse momento eu estou tentando com a minha equipe, fazer uma curva na nossa atividade: criar mais manuais para que o controle primário fique nas secretarias, nós estamos muito sobrecarregados com isso ainda, por exemplo, a controladoria ao longo do tempo, culturalmente, ela estabeleceu o fluxo da execução da despesa aonde 100\% da despesa passava pela controladoria, isso é impensável para uma unidade central de controle".

Em Uberlândia, a Controladoria está focada na despesa pública, que é um fator que prejudica potencialmente a efetividade do $\mathrm{SCl}$ de Uberlândia, visto que não possuem técnicas modernas de controle, como matriz de risco, amostragem, controle concomitante e avaliações por indicadores. Ao contrário de Uberlândia, que possui maior atenção em suas atividades em controle operacional, com o controle das despesas, o SCl de Belo Horizonte possui o foco no acompanhamento da gestão municipal, de modo que acompanhe a execução do planejamento público e a execução do gasto, concomitantemente.

Pelo fato de haver uma demanda considerável de mão de obra, devido à alta quantidade de compras que um município do porte de Uberlândia realiza, percebe-se a insatisfação e desmotivação da equipe de servidores, que desempenham trabalhos meramente operacionais. Portanto, o fato de haver uma limitação de pessoal no setor é um fator contingencial prejudicial no processo de institucionalização na Controladoria em questão.

Ainda de acordo com um dos princípios de controle, não é possível controlar atividades que a própria equipe desenvolveu. Assim, a existência de atividades operacionais de acompanhamento de gastos na controladoria prejudica a função principal, que é controlar.

Na controladoria de Uberlândia, o Controlador Geral e outros dois servidores, desde o ano de 2017, com a nova gestão, estão tentando desvincular o setor de controle interno do setor que é responsável pelo trabalho operacional. Portanto, através da Comissão de Auditoria de Preços e Necessidade da Des- 
pesa Pública, estão executando cursos e capacitação em todas as secretarias municipais, para que as próprias secretarias executem parte dessas atividades que não são de atribuição das controladorias, de modo que, se institucionalize essa rotina na prefeitura. Todavia, ainda estão em fase de convencimento dos servidores do município sobre a importância dessa prática para os resultados organizacionais.

O fato de a maioria dos servidores de ambas as controladorias possuírem experiência em gestão pública e serem graduados em diversas áreas afins, como administração, ciências contábeis e direito, auxilia o desempenho de suas funções de controle do bem público. Além disso, ambas as controladorias possuem servidores com outras capacitações como engenheiros, por exemplo, visto que, nas atividades de controle de obras e licitações para execução de alguma construção na administração pública, os outros servidores do controle, com capacitação em áreas jurídicas e financeiras, não iriam contribuir para um melhor serviço nesses casos. Isso corrobora os achados dos estudos de Razak, Abdullah e Dali (2017), Mutiara, Fachrudin e Irawati (2019) e Dewi, Azam e Yusoff (2019) sobre a influência positiva da competência dos recursos humanos no sistema de controle interno e qualidade das informações públicas.

Em relação à Controladoria de Belo Horizonte, praticamente todas as práticas em "Sim" (Tabela 5) estão institucionalizadas no $\mathrm{SCl}$, apesar das diretrizes internacionais de controle interno do COSO ainda estarem em fase de adoção. Ou seja, é o momento de conseguir obter apoio da equipe, demonstrando a importância da prática e conscientizando para conseguir apoio na implementação efetiva (Gondo \& Amis, 2013). Corrroborando também com os achados de Monteiro (2015) que elenca como uma das principais barreiras no sistema de controle interno público brasileiro a falta de uma cultura de gestão de risco.

Em ambas as controladorias, existem práticas de controle interno que estão sendo inicialmente implementadas nos municípios. No caso de BH, são as diretrizes internacionais de controle interno COSO nos processos de auditoria, uma iniciativa do Controlador Geral Municipal e da Subcontroladora de Auditoria, ambos servidores do TCE/MG há mais de 15 anos. Ou seja, o capital institucional é um fator positivo e relevante no processo de institucionalização, conceituado etapa de teorização.

Nos casos analisados, foram identificados os Controladores Gerais, Assessores e Subcontroladores como atores com poder internos com alto capital institucional. Esses atores estão movendo esforços conjuntamente desde 2017, com a nova equipe de alto escalão da controladoria, para implementarem novas práticas e rotinas importantes para um efetivo serviço de controle interno municipal, cada qual com suas capacidades técnicas específicas.

Corroborando com os achados de Lino et al. (2019), o capital institucional é acumulado, quando "(i) recebe apoio de atores com poder que passam a servir de fonte de legitimação, e (ii) as ideias, valores, conceitos e procedimentos de uma nova prática vão sendo implantados, aceitos e sedimentados dentro da organização" (Lino et al., 2019, p. 6).

Os autores Tolbert e Zucker (1996) e Giondo e Amis (2003) afirmam existir a necessidade de que todos os atores da organização possam integrá-la já sabendo das suas obrigações para que, assim, por meio de carriers e outros mecanismos institucionais, haja uma perpetuação dessas estruturas e práticas por um longo tempo.

Desse modo, elaborou-se a Tabela 6 com os fatores institucionais identificados nos dois casos analisados e envolvidos nos processos de institucionalização, como fatores facilitadores ou bloqueadores para a institucionalização de novas práticas de controle em municípios.

A Tabela 6 visa resumir quais os fatores institucionais ou contingenciais influenciam de modo positivo ou negativo no processo de institucionalização nas unidades de análises estudadas. Um fator institucional positivo utilizado em ambos os casos consiste nos mecanismos institucionais, sejam: coercitivos, 
normativos e miméticos, utilizados como meios de legitimação a legalmente sancionada, moralmente governada e a culturalmente amparada (Scott, 2003).

Tabela 6 - Fatores envolvidos no Processo de Institucionalização de Práticas de Controle Interno nas Prefeituras analisadas

\begin{tabular}{|c|l|l|}
\hline Efeitos & \multicolumn{1}{|c|}{ Fatores institucionais } & \multicolumn{1}{|c|}{ Fatores contingenciais } \\
\hline Positivos & $\begin{array}{l}\text { - Isomorfismo de práticas, (i) coercitivo, (ii) normativo } \\
\text { (iii) mimético } \\
\text { - Carriers - fluxos de informações e formulários; manuais de procedimentos } \\
\text { - Capital institucional - apoio interno e externo de atores com poder }\end{array}$ & $\begin{array}{l}\text { - Normas definidas } \\
\text { - Estrutura de pessoal (mínima) } \\
\text { - Capacitação das equipes }\end{array}$ \\
\hline Negativos & $\begin{array}{l}\text { - Resistência dos atores (i) conflito de lógicas institucionais; (ii) complexidade institucio- } \\
\text { nal - atores com poder não concordam/não apoiam a prática; (iii) falta de compreensão } \\
\text { do conteúdo da prática } \\
\text { - Baixa teorização } \\
\text { - Decoupling (adoção cerimonial) }\end{array}$ & $\begin{array}{l}\text { - Limitação de Pessoal; } \\
\text { - Dificuldades Financeiras; } \\
\text { - Tecnologia de Informação- TI }\end{array}$ \\
\hline
\end{tabular}

Exemplificando a utilização desses mecanismos nos casos analisados, percebe-se o isomorfismo normativo quando os servidores da Controladoria Geral de BH afirmam possuir trocas de informações e interação com organizações como CGU e CONACl, órgãos profissionais de controle interno com referência nacional, através de cursos, capacitação, trocas de experiência e encontros técnicos. Além disso, a relação da controladoria com esses órgãos também se caracteriza como fonte para isomorfismo mimético, a partir do momento que projetos executados no município de BH possuem material didático repassado pela CGU diretamente para o setor de controle municipal, por meio dos projetos "Aluno Auditor", "Ouvidor Itinerante", "Um Por Todos e Todos Por Um”, utilizado e fomentado pela CGU e Controladoria Geral do Distrito Federal (CGDF).

Por fim, o mecanismo coercitivo é presente na rotina do município há muitos anos, sendo um hábito dos servidores do controle interno ao implementarem legislações municipais, sejam elas em forma de lei, decreto ou portaria, para forçar os servidores a implementarem os procedimentos e passando manuais para minimizar as dúvidas e padronizar essas práticas.

Já o controle interno em Uberlândia, através do monitoramento do Ministério Público e CGU, começou a pensar na Transparência dos atos e fatos públicos no ano de 2014, com uma notificação do Ministério Público, pelo fato do município não estar naquele momento, atendendo as exigências legais da LRF e LAI. Além disso, pela maior proximidade geográfica, afirmam participar de workshops em São Paulo, realizados pelo Ministério do Planejamento na área de Compras Públicas, como modo de capacitação dos servidores municipais. Também participam periodicamente de cursos e encontros realizados pela Associação dos Municípios da Microrregião do Vale do Paranaíba (AMVAP), ao qual são associados, o que é caracterizado como isomorfismo normativo.

Nas duas controladorias, são utilizados manuais de procedimentos, treinamento e capacitação para difusão das práticas internas. $\mathrm{O} \mathrm{SCl}$ de $\mathrm{BH}$ possui diversos manuais para transmissão dos conhecimentos do setor. Já o SCl de Uberlândia também possui manuais internos de procedimentos, que não são muitos devido à limitação de pessoal e alta demanda de solicitações de compras que o município possui. Essas constatações corroboram os estudos de Scott (2014) e Greenwood et al. (2008), que apontam que os indivíduos utilizam de carriers como manuais e treinamentos para a transmissão de instituições, importante instrumento de teorização dos servidores (Giondo \& Amis, 2003).

Outro aspecto destacado e identificado como potencial motivador no processo institucional consiste na legitimação. Em 2009, o CONACl apresentou a Proposta de Emenda Constitucional no 45, que visava tornar obrigatórias as atividades de Auditoria, Controladoria, Ouvidoria e Correição para todos os órgãos de controle interno da administração pública. O fato do município de Belo Horizonte ter adotado esse 
modelo de controladoria, sem haver um mecanismo coercitivo até o momento, demonstra um fator de busca por legitimação.

Um dos fatores que está dificultando a institucionalização de novas práticas de controle, como discutido por Azevedo (2016), é a resistência e background contrário dos atores ao conteúdo da norma, tais como a falta de aceitação dos servidores sobre a importância dos procedimentos de controle e o não desperdício de recurso público. Essa resistência é exposta nas evidências dos Entrevistados 12 e 13:

E13: Então a dificuldade é você colocar na cabeça da pessoa que aquilo é importante. Você colocar na cabeça do gestor que precisa atender aquela demanda dele que o preço é importante. Então falando das dificuldades da comissão de preço. No caso igual eu falei, a mudança de cultura é traumática porque você tirar da zona de conforto um agente político que tem bastante influência é o maior desafio.

E12: ...então a maior dificuldade são as pessoas quererem mudar, a gente diz que é cultura, igual por exemplo, estamos com um processo que vai mudar toda a estrutura de trabalho na prefeitura, a pessoa que for fazer uma requisição, ela não vai fazer uma simples requisição, ela vai ter que analisar por que você dali vai ter que estudar a empresa que você vai trabalhar. Eu vejo a cultura como nosso maior problema por que eu vejo que dificulta, o intuito do controle interno é ajudar.

Como discutido por Azevedo (2016), a resistência pela aceitação de novas práticas pode ser decorrente da falta de teorização que essas estão recebendo pelo condutor da introdução da nova prática. Os atores, por não entenderem a nova lógica proposta, tendem a resistir à sua adoção, causando impedimento na adoção, ou adoção cerimonial.

$\mathrm{Na}$ Controladoria de Uberlândia, algumas práticas estão limitadas e não estão institucionalizadas na organização, sendo a principal delas a auditoria ou controle posterior. Segundo os entrevistados, esse fator deve-se à resistência dos atores em aceitar as mudanças impostas pelo contexto organizacional. Os processos de auditoria começaram a ser executados apenas a partir de 2017, com a nova equipe de Controlador Geral e Assessores. Em 2017 e 2018, foram executadas um total de seis auditorias, o que é considerado um número relativamente baixo pela quantidade de recursos públicos que circulam na prefeitura. Entretanto, não há auditores internos no município, ou seja, não há cargo exclusivo para essa função, devido à limitação de pessoal, por motivos políticos e calamidade financeira. Desde o ano de 2013, se aguarda a realização de concurso público.

Portanto, identifica-se a resistência como um fator institucional presente nesse processo e o fator contingencial em relação a limitação de pessoal. A resistência é um modo de rejeição de mudanças de rotinas por parte dos servidores, ocorrendo quando os interesses internos divergem completamente dos interesses externos ou quando as organizações acreditam ter pouco a perder caso não institucionalizem determinadas práticas (Oliver, 1991).

Em se tratando dos processos de institucionalização em questão, identificou-se que algumas práticas de controle estão sendo executadas de modo cerimonial ("evitação") na Controladoria de Uberlândia.

Por meio das entrevistas, foi identificado que o controle interno de Uberlândia possui o foco no controle primário nos processos de compras públicas, sendo que todas as compras passam pela Controladoria antes de serem realizadas e independente do valor monetário. Entretanto, quando analisado o Relatório de Controle Interno do Município, disponibilizado no Portal do TCE/MG, é colocado que a Controladoria realiza trabalhos como solicitado pelas Legislações, o controle interno de modo prévio, concomitante e posterior. No entanto, o Entrevistado 9 expõe de outra forma: 
E9:"Ao longo do tempo, se estabeleceu uma cultura que seria mais ou menos assim:"podemos errar que a controladoria vai achar esse erro", então ao longo do tempo, a controladoria demandou muita energia no controle primário, e se distanciou muito do controle macro que é aquele do acompanhamento, dos resultados, do sucesso, das ações orçamentárias por exemplo, e de auditorias in loco, bem como perdeu um pouco a chance de ter mais manuais, então nesse momento eu estou tentando com a minha equipe, fazer uma curva na nossa atividade: criar mais manuais para que o controle primário fique nas secretarias, nós estamos muito sobrecarregados com isso ainda, por exemplo, a controladoria ao longo do tempo, culturalmente, ela estabeleceu o fluxo da execução da despesa aonde $100 \%$ da despesa passava pela controladoria, isso é impensável para uma unidade central de controle, tanto é que em 2016 pela resolução número 2 do tribunal de contas de Minas estabeleceu que "a unidade central deve buscar olhar a execução da despesa, mediante processo seletivo". Ainda continuamos fazendo controle primário de muita coisa, estamos aos poucos tirando isso da controladoria, deixando na secretaria, pra gente trabalhar oportunamente conforme conveniência e a necessidade para nos dedicarmos mais ao controle do acompanhamento da execução, o orçamento né, mas isso ainda é incipiente, tá no início ainda".

Nesse sentido, devido à contradição entre dados coletados, percebe-se que o controle concomitante e posterior no município de Uberlândia ainda é realizado de modo cerimonial, como meio de sobrevivência externa, proteção das pressões institucionais e busca por legitimidade, como discutido por Oliver (1991). Sendo, portanto, um fator dificultador da institucionalização, conceituado decoupling. Corroborando com Sediyama et al. (2017) constatando a existência de controles internos cerimoniais em municípios brasileiros.

Outro fator contingencial identificado em ambos os casos estudados, com força negativa no processo institucional, são os softwares e as tecnologias da informação.

O software e as tecnologias de informação funcionam como um mecanismo facilitador no processo institucional, pois aumentam a produtividade das atividades de controle interno. Entretanto, por meio dos dados da pesquisa, percebeu-se que esse é um fator limitador nos dois municípios analisados, sendo indicado por todos os entrevistados no estudo como um fator que dificulta as atividades de controle interno, até permitindo o surgimento do decoupling.

Em Uberlândia, apesar do município possuir uma empresa que forneça softwares, chamada PRODAUB, essa apresenta problemas na prestação dos serviços, conforme exposto pelo Entrevistado 14.

E14: OSEl, ele tá 99\% né, por que é uma decisão de governo, então tem um apoio muito grande dos secretários que estão envolvidos, só que tem uma resistência muito grande da PRODAUB por que ela hoje tem um problema financeiro também, por que ela vive da prefeitura né, apesar dela ser uma empresa pública, ela vive da prefeitura, que a gente é o único acionista dela, e o único que ela presta serviço hoje.

A Controladoria Geral da prefeitura de Uberlândia está reunindo esforços para conseguir implantar um Sistema Eletrônico de Informações (SEI) que, criado pelo Tribunal Regional Federal (TRF) da $4^{\text {a }}$ região e pelo Ministério do Planejamento, Orçamento e Gestão, é um sistema grátis, sendo necessário apenas o Governo fazer a solicitação de adesão. A partir disso, todos os trâmites que acontecem por meio de documentos físicos aconteceriam online. Um servidor da CGM de Uberlândia participou de um workshop em São Paulo, organizado pelo Ministério do Planejamento, adquirindo conhecimento desse sistema e articulando esforços conjuntos com o Controlador para convencimento da necessidade de implantação na Prefeitura.

Aspectos assim prejudicam a implementação do sistema de informação e consequentemente as atividades de controle interno realizadas no município. Vale frisar que, cada Controladoria possui o seu contexto organizacional específico, portanto, as análises dessa pesquisa não buscam generalizar os 
seus achados ou realizar comparações entre os municípios, mas demonstrar que o processo de institucionalização pode ocorrer de diversas formas e os fatores institucionais ou fatores contingenciais que envolvem esse processo, pode variar de organização para organização.

Com base nos resultados de pesquisa, é evidente que a institucionalização do $\mathrm{SCl}$ nos municípios em análise é lastreada no ambiente institucional que permeia as decisões organizacionais. Evidentemente que pela proximidade do município de Belo Horizonte por ser capital do estado-membro de Minas Gerais e pela proximidade da sede do governo e do Judiciário, tem uma performance mais efetiva quanto se analisa seu sistema de controle interno. Importa-se evidenciar que em termos administrativos o controle interno não se estabelece de forma independente do controle externo. Neste sentido, a proximidade e inclusive, o perfil dos gestores públicos do município, contribui para um nível mais amplo de governança municipal.

É com base nos resultados que também fica evidente que apesar de Uberlândia ser considerado um município de grande porte no Brasil, há ainda uma lacuna evidente se considerar o escopo do SCI de Belo Horizonte. Nesta lacuna, fica patente o desafio de articular o desenho de políticas de SCl com a implementação deste controle em órgãos municipais. Por mais que as diretrizes legais são construídas no intuito de contribuir para m melhor nível de eficiência, é importante, que o mimetismo seja levado em consideração como mecanismo que enfraquece a performance municipal. É patente os efeitos negativos sob o corpo burocrático tornando dissociando a atuação dos agentes públicos dos atos normativos pronunciados.

Isso quer dizer que os formuladores de políticas públicas fiscais no Brasil precisam levar em consideração a heterogeneidade no que tange ao controle interno dos municípios no Brasil. Ao se tomar como efeito comparativo municípios de grande porte, neste estudo foi possível observar uma certa discrepância em termos de estruturação de uma governança capaz de acompanhar as demandas do executivo local. A dissociação entre o arcabouço legal e a ação dos gestores torna ainda mais clara esta necessidade da construção de políticas de controle mais participativas (bottom up) que levam em consideração a heterogeneidade das organizações públicas em Minas Gerais e no Brasil.

\section{CONSIDERAÇÕES FINAIS}

Os resultados da pesquisa indicam que mecanismos isomórficos, coercitivos, miméticos e normativos são utilizados no processo de institucionalização de novas práticas de controle interno nos governos subnacionais analisados, sendo as práticas adotadas sobretudo em decorrência de pressões e monitoramento de órgãos externos de controle, como os Tribunais de Contas (mecanismo coercitivo).

A Controladoria de Belo Horizonte possui parcerias com significativo número de organizações de controle, tais como CGU e CONACI (órgãos de controle interno) e TCE/MG (auxiliar no controle externo), fato que facilita a troca de informações e a homogeneidade no campo organizacional. Além disso, algumas práticas de controle interno não reguladas normativamente são realizadas no controle interno da capital mineira, devido ao fato dessas parcerias auxiliarem em projetos que estimulam o controle social. Portanto, pôde-se inferir que esse relacionamento com outros órgãos da administração pública auxilia a legitimação da Controladoria de Belo Horizonte e contribui para a adoção de práticas através de um processo de isomorfismo normativo, visto que, ao fazerem parte desses grupos, as organizações procuram adotar as mesmas práticas aceitas e legitimadas. 
Por outro lado, no que concerne à relação com outras entidades, a Controladoria de Uberlândia possui troca de experiências apenas com a Associação de Municípios da Microrregião do Vale do Paranaíba (AMVAP). Além disso, conjugado às dificuldades inerentes à pouca interação com organizações, a falta de autonomia nas atividades é outro fator identificado como importante dificultador à adoção de práticas de controle interno. Constatou-se que o setor de controle interno do município de Uberlândia possui pouca autonomia em suas atividades, uma vez que as atividades de controle primário (controle prévio das compras públicas), por exemplo, decorreram de exigência do prefeito municipal, além do fato de que determinadas decisões relevantes da controladoria devem primeiramente passar pelo Secretário de Governo, ou seja, há autoridade por parte do executivo para influenciar nas atividades de controle municipal, o que interfere na independência do órgão.

Destaca-se que diversas práticas previstas em normativos sobre controle interno estão implantadas nos municípios analisados. No entanto, nem todas estão efetivamente institucionalizadas, o que permitiu inferir que essas são adotadas apenas de modo cerimonial, ou seja, há presença do decoupling em práticas de controle concomitante, sobretudo na controladoria de Uberlândia.

Os resultados ainda indicam, como decoupling, que há resistência dos servidores à adoção de novas práticas de controle interno, o que influencia no seu processo de institucionalização. Nesse sentido, para que essa resistência diminua, sugere-se a implantação de medidas para que essas práticas tenham alguma forma de legitimação externa, o que permitiria o delineamento de uma agenda de adoção.

Como principais fragilidades, foram identificados na Controladoria de Belo Horizonte problemas relacionados às tecnologias de informação, uma vez que o município possui diversos softwares não integrados entre si, o que tem dificultado a prestação de contas mensal e anual para o TCE/MG. Além disso, a realização de auditorias, elaboração de relatórios e outros tipos de atividades de controle seriam facilitadas se houvesse integração e fossem promovidas melhorias nos softwares do município.

No caso da Controladoria de Uberlândia, têm-se como principal ponto passível de melhoria a baixa autonomia do setor, que gera implicações na independência de suas atividades de controle. Essa constatação foi levantada por meio das evidências coletadas nas entrevistas e pelo próprio organograma do município, que vigora desde 1994, e que dispõe o órgão da Controladoria como subordinado ao Prefeito Municipal e ao Secretário Municipal de Governo, em desacordo com o já consolidado pela literatura.

Além disso, as atividades de controle interno em Uberlândia são historicamente focadas em trabalhos operacionais, especificamente no trabalho de autorização da despesa pública, que seria de responsabilidade das próprias secretariais municipais. Esse fator dificulta a execução de atividades técnicas, como as inerentes a contadores, advogados, engenheiros e administradores lotados no setor, uma vez que muitos deles se mostraram desestimulados a execução desse tipo de trabalho, devido à sobrecarga das atividades operacionais. Para que haja melhorias nesse aspecto, é necessário que haja a conscientização de todos os servidores municipais sobre quais são as atribuições do controle interno e das secretarias municipais. Para tanto, a elaboração de manuais de procedimentos de controle auxiliaria a mudança na mentalidade dos servidores e, portanto, sua conscientização, o que já se encontra em andamento na Controladoria de Uberlândia, por meio dos memorandos divulgados pela comissão de Auditoria de Preços e Necessidade da Despesa Pública.

Em termos de agenda de pesquisa, este estudo aproxima o leitor de um debate recente no campo da administração pública no Brasil e no mundo. A adoção dos isomorfismos neoinstitucionalistas como elemento chave para analisar a atuação dos gestores públicos de SCl locais deixam evidente a interrelação 
do desenho de políticas públicas e sua implementação efetiva em níveis locais. Em se tratando de informações gerenciais, a performance do SCl está diretamente ligada a operacionalização dos instrumentos de controle pelos níveis mais operacionais do executivo local. Isto quer dizer que a atuação do $\mathrm{SCl}$ em 'nível da rua', ou seja, no seu nível mais operacional, deveria estar correlacionada e integrada à formulação das macropolíticas de controle interno no setor público - como aquelas desenvolvidas pela CGU. Se considerar que é na implementação da política que se apresenta as principais fragilidades - sobretudo os conflitos de valores -, ou seja, onde mais há probabilidade de haver o decoupling, o estímulo a uma construção de política pública dialogada e participativa - entre níveis federativos e entre os poderes - é pressuposto para a melhoria da performance dos SCl em nível local. Isso se dá, principalmente, em compartilhamento de know how, tecnologias, conhecimento e experiências.

Considerando e tomando Belo Horizonte como evidência de boas práticas de $\mathrm{SCl}$ - apesar de suas fragilidades, infere-se que o estímulo a maior interação entre o ente municipal com o ente estadual, além da interação com órgãos do judiciário e também da sociedade, pode promover a melhor performance dos $\mathrm{SCl}$ em nível local. Evidentemente, que este controle ao se correlacionar com o controle externo e também o societal pode trazer uma melhoria sobremaneira da qualidade das informações públicas e uma diminuição substantiva da opacidade estatal.

Em termos de pesquisas futuras este estudo aponta três big questions consonantes ao $\mathrm{SCl}$ em nível local: i) as políticas públicas de $\mathrm{SCl}$ (em nível macro) tem levado em consideração a experiência dos gestores de 'nível da rua' no que tange a performance das controladorias municipais? ii) qual a relação entre a performance do SCl em nível local e o melhoramento da qualidade da informação pública? iii) qual a relação entre decoupling e discricionariedade no contexto dos $\mathrm{SCl}$ em nível local? Em termos de proposição de agenda futura de pesquisa, estas perguntas norteadoras poderão dar luz ao debate tão caro ao campo da administração pública que é da performance das organizações que permeiam esse contexto e o alcance do interesse público.

\section{REFERÊNCIAS}

Alves, A. G. de S.; Moraes, V. F.de J. (2016). O Sistema de Controle Interno da Gestão Pública do Poder Executivo do Município de Patos/PB. Revista Evidenciação Contábil \& Finanças, 4 (3), 56-71. https://doi. org/10.18405/recfin20160304

Anderson, R., Maks, H., Klaassen, H. (2019). An exploratory study assessing compliance among municipal controllers and the possible explanations for their degree of compliance. Journal of Public Affairs, 1-13. https://doi.org/10.1002/pa.2068

Araújo, D. J. C. et al. (2016). Unidades de Controle Interno dos Municípios Brasileiros: Análise sob a ótica do COSO II. Revista Universo Contábil, 12 (2). https://doi.org/10.4270/ruc.2016213

Araújo, R. M. de et al. (2017). Controle Interno no Rio Grande do Norte: Um Estudo na Visão dos Controllers Municipais. Nucleus, 14 (1), 79-94. https://doi.org/10.3738/1982.2278.2143

AMM. Associação Mineira de Municípios. (2018). Caracterização econômica das regiões de planejamento. Disponível em: <https://portalamm.org.br/caracterizacao-economica-das-regioes-de-planejamento/>. Acesso em: 22 de novembro de 2018.

Azevedo, R. R. de. (2016). Resistências ao planejamento de resultados e a lógica orçamentária dominante em municípios. Tese de Doutorado. Universidade de São Paulo.

Bae, K. B., \& Kim, D. (2016). The Impact of Decoupling of Telework on Job Satisfaction in U.S. Federal Agencies. The American Review of Public Administration, 46(3), 356-371. doi:10.1177/0275074016637183. 
Berger, P. L.; Luckman, T. (1967). The social construction of reality.

Berger, P. L; Luckmann, T. (2002). A construção social da realidade. 22. Ed. São Paulo: Vozes.Boxenbaum, E., \& Jonsson, S. (2017). Isomorphism, diffusion and decoupling: Concept evolution and theoretical challenges. In R. Greenwood, C. Oliver, T. B. Lawrence, \& R. E. Meyer (Eds.), The Sage Handbook of Organizational Institutionalism (pp. 79-104). London/UK: SAGE Publications.

Broadbent; J.; Laughlin, R. (2003). Control and legitimation in government accountability process: the private finance iniciative in the UK. Critical Perspectives on Accounting, 14, 23-48. https://doi.org/10.1006/ cpac.2001.0525

Burns, J.; Scapens, R. W. (2000). Conceptualizing management accounting change: an institutional framework. Management Accounting Research, 11 (1), 3-25. https://doi.org/lO.I006/mare. 1999.0119

Carvalho, C. A.; Vieira, M. M. F. (2012). Organizações, cultura e desenvolvimento local: a agenda de pesquisa do Observatório da Realidade Organizacional. GESTÃO. Org-Revista Eletrônica de Gestão Organizacional, 10 (3).

Castro, D. P. de. (2015). Auditoria, Contabilidade e Controle interno no Setor Público: Integração das áreas do ciclo de gestão: Contabilidade, Orçamento e Auditoria e Organização dos Controles Internos, como suporte à Governança Corporativa. $6^{\mathrm{a}}$ ed. São Paulo: Atlas.

Cavalcante, D. S.; Peter, M. D. G. A.; Machado, M. V. V. (2011). Organização dos órgãos de controle interno municipal no estado do Ceará: um estudo da região metropolitana de Fortaleza. Advances in Scientific and Applied Accounting- ASAA.

Cruz, M. do C. M. T.; Silva, T. A. B.; Spinelli, M. V. (2016). O Papel das Controladorias Locais no Cumprimento da Lei de Acesso à Informação pelos Municípios Brasileiros. Cadernos EBAPE. BR, 14 (3). http://doi. org/10.1590/1679-395131556

Dewi, N. F., Azama, S. M. F., Yusoff, S. K. M. (2019). Factors influencing the information quality of local government financial statement and financial accountability. Management Science Letters, 9(9), 1373-1384. doi: $10.5267 /$ j.msl.2019.5.013

DiMaggio, P. J.; Powell, W.W. (1983). The iron cage revisited: Institutional isomorphism and collective rationality in organizational fields. American Sociological Review, 48 (2), 147-160. https://doi.org/10.2307/2095101

Eisenhardt, K. M. (1989). Building Theories From Case Study Research. The Academy of Management Review, 14 (4). https://doi.org/10.5465/amr.1989.4308385

Fernandes, L. D. L. F.; Borges, T. J.; Leite Junior, M. C. R. (2017). Auditoria e Controle Interno no Setor Público e sua Contribuição para a Democracia. Revista da Universidade Vale do Rio Verde, 15 (1), 642-654. http:// doi.org/10.5892/ruvrd.v15i1.4044

Frumkin, P., \& Galaskiewicz, J. (2004). Institutional isomorphism and public sector organizations. Journal of Public Administration Research and Theory, 14(3), 283-307.https://doi.org/https://doi.org/10.1093/jopart/ muh028Gondo, M. B.; Amis, J. M. (2013). Variations in practice adoption: The roles of conscious reflection and discourse. Academy of Management Review, 38 (2), 229-247. https://doi.org/10.5465/amr.2010.0312

Greenwood, R. et al. (2008). Introduction. In: Greenwood, R. et al. (Eds.). The Sage Handbook of Organizational Institutionalism. Londres: Sage.

Guerreiro, R.; Pereira, C. A.; Frezatti, F. (2008). Aplicação do modelo de Burns e Scapens para avaliação do processo de institucionalização da contabilidade gerencial. Organizações \& Sociedade, 15 (44), 45-62. https://doi.org/10.1590/S1984-92302008000100003

Johnson, A. D., \& Vaughn, M. S. (2016). Decoupling and Police Organizational Structure. Administrative Theory \& Praxis, 38(3), 157-167. doi:10.1080/10841806.2016.1173942.

Kelm, M. L. et al. (2014). Institucionalização das iniciativas socioambientais das organizações: interfaces entre a teoria do desenvolvimento social de Habermas e o isomorfismo da teoria institucional. Cadernos EBAPE. BR, 12, 401-415. 
Kewo, C. L. (2017). The influence of internal control implementation and managerial performance on financial accountability local government in Indonesia. International Journal of Economics and Financial Issues, 7 (1), 293-297.

Lacombe, B. M. B.; Chu, R. A. (2008). Políticas e práticas de gestão de pessoas: as abordagens estratégica e institucional. Revista de Administração de Empresas, 48 (1), 25-35. http://doi.org/10.1590/S003475902008000100003

Lartey, P.Y., Kong, Y., Bah, F. B. M., Santosh, R. J., Gumah, I. A. (2020). Determinants of Internal Control Compliance in Public Organizations; Using Preventive, Detective, Corrective and Directive Controls. International Journal of Public Administration, 43 (8), 711-723. https://doi.org/10.1080/01900692.2019.1645689

Lino, A. F., Carvalho, L. B., Aquino, A. C. B., \& Azevedo, R. R. (2019). A falta de trabalho institucional e mudanças organizacionais incompletas em municípios brasileiros. Revista de Administração Pública, 53 (2). https://doi.org/10.1590/0034-761220170404

Loureiro, M. R., Abrucio, F. L., Olivieri, C., \&Teixeira, M. A. C. (2012). Do controle interno ao controle social: a múltipla atuação da CGU na democracia brasileira. Cadernos Gestão Pública e Cidadania, 17 (60). http:// doi.org/10.12660/cgpc.v17n60.3980

Maffezzolli, E. C. F.; Boehs, C. G. E. (2008). Uma reflexão sobre o estudo de caso como método de pesquisa. Revista FAE, Curitiba, 11 (1), 95-110.

Mckinnon, J. (1988). Reliability and Validity in Field Research: Some Strategies and Tactics. Accounting, Auditing \& Accountability Journal, 1(1), 34-54. https://doi.org/10.1108/EUM0000000004619

Meyer, J. W.; Rowan, B. (1977). Institutionalized Organizations: Formal Structure as Myth and Ceremony. American Journal of Sociology, 83(2), 340-363.

Mohammed, A. (2018). Effect of internal control on revenue collection in Kintampo Municipal Assembly. Tese de Doutorado. University of Cape Coast.

Monteiro, R. P. (2015). Análise do sistema de controle interno no Brasil: objetivos, importância e barreiras para sua implantação. Revista Contemporânea de Contabilidade, 12 (25), 159-188. http://dx.doi. org/10.5007/2175-8069.2015v12n25p159

Mutiara, R., Fachrudin, K. A., \& Irawati, N. (2019). Analysis of the Management Information System Implementation of Local Government Asset, Human Resources Capacity and Government Internal Control Systems on North Sumatra's Provincial Government Financial Statements Quality. European Journal of Economic and Financial Research, 3 (5), 122-141. http://dx.doi.org/10.5281/zenodo.3547836

Nogueira, S. P. da S.; Jorge, S. M. F. (2017). The perceived usefulness of financial information for decision making in Portuguese municipalities: The importance of internal control. Journal of Applied Accounting Research, 18 (1), 116-136. https://doi.org/10.1108/JAAR-05-2014-0052

Nowell, B.; Albrecht, K. (2019). A Reviewer's Guide to Qualitative Rigor. Journal of Public Administration Research and Theory, 29(2), 348-363. https://doi.org/10.1093/jopart/muy052

O'Donnell, G. (1998). Accountability horizontal e novas poliarquias. Lua nova, 44 (98), 27-54. https://doi. org/10.1590/S0102-64451998000200003.

Oliver, C. (1991). Strategic responses to institutional processes. Academy of Management Review, 16 (1), 145-179. https://doi.org/10.2307/258610

Olivieri, C. (2016). Atuação dos controles internos e externos ao Executivo como condicionante de execução de investimento em infraestrutura no Brasil. Rio de Janeiro: IPEA.

Pacheco, F. L. (2002). O isomorfismo institucional nos teatros da região metropolitana do Recife. Anais do encontro Nacional dos Programas de Pós-graduação em Administração.

Patton, M. Q. (2015). Qualitative Research \& Evaluation Methods. Thousand Oaks, CA: SAGE Publications, Inc. 
Patz, R. (2018) Leaking, leak prevention, and decoupling in public administrations: the case of the European Commission, West European Politics, 41:4, 1049-1071, DOI: 10.1080/01402382.2017.1394103.

Pederneiras, M. M. M. et al. (2018). Marcos regulatórios do controle interno: um estudo na ambientação com o controle externo e o controle social no Brasil. BASE - Revista de Administração e Contabilidade da Unisinos. 15(1), 2-17. https://doi.org/10.4013/base.2018.151.01

Razak, J., Abdullah, M., \& Dali, N. (2017). The Effect of Human Resources Competence on the Government Implementation of Internal Control System, Accrual Based Accounting Standards and the Quality of Local Government's Financial Report. JPEP- Jurnal Progres Ekonomi Pembangunan, 2(2), 15-40.

Robles, B. (2011). La entrevista en profundidad: una técnica útil dentro del campo antropofísico. Cuicuilco, 18 (52), 39-49.

Rusnindita, K. et al. (2017). Determinan Kualitas Sistem Pengendalian Internal Pemerintah. Journal of Research and Applications: Accounting and Management, 2 (2), 141-157.

Scott, W. R. (2003). Institutional carriers: reviewing modes of transporting ideas over time and space and considering their consquences. Industrial and Corporate Change. Vol. 12 (4), 879- 894. https://doi. org/10.1093/icc/12.4.879

Scott, W. R. (2014). Institutions and Organizations: Ideas, Interests, and Identities (4a). London: Sage Publications Ltd.

Sediyama, G. A. S.; Aquino, A. C. B; Lopes, G. B. (2017). A difusão das mudanças da contabilidade pública me municípios. Contabilidade Vista \& Revista, 28 (2), 78-100.

Teixeira, M. A. C.; Cruz, M. do C. M. T.; Silva, T. A. B.. (2014). Análise das controladorias municipais brasileiras frente ao modelo da Controladoria-Geral da União: avanços e desafios na promoção da transparência e do controle social. In XIX Congreso Internacional del CLAD sobre la Reforma del Estado y de la Administración Pública, Quito, Ecuador.

Tolbert, P. S.; Zucker, L. G. (1996). The Institutionalization of Institutional Theory. In: Clegg, S. R.; Hardy, C.; Nord, W. R. (Eds.). Handbook of Organization Studies. London: Sage, 175-190.

Tuttle, B.; Dillard, J. (2007). Beyond competition: Institutional isomorphism in US accounting research. Accounting Horizons, 21 (4), 387-409. https://doi.org/10.2308/acch.2007.21.4.387

WHO. World Health Organization. (1994). Qualitative research for health programmes. Geneva: Division of Mental Health. 